\title{
Efeito do exercício físico e da administração de testosterona na consolidação de fraturas de tíbia em ratos
}

\author{
Effects of exercise and testosterone administration \\ on tibia fracture healing in rats
}

\section{Francisco Valmor Macedo Cunha ${ }^{[a]}$, Oséas Florêncio de Moura Filho ${ }^{[b]}$, Felipe Scipião Moura ${ }^{[c]}$, Maria do Carmo de Carvalho e Martins ${ }^{[\mathrm{d}]}$}

[a] Estudante de graduação em Fisioterapia da Faculdade NOVAFAPI, bolsista do Programa Institucional de Bolsa de Iniciação Científica (PIBIC-NOVAFAPI), Teresina, PI - Brasil, e-mail: orfeuyeuridice@yahoo.com.br

[b] Mestre em Terapia Intensiva pela Sociedade Brasileira de Terapia Intensiva (SOBRATI), Instituto de Ensino e Pesquisa em Fisioterapia Clínica, Teresina, PI - Brasil, e-mail: oseasbr@yahoo.com.br

[c] Estudante de graduação em Medicina da Faculdade NOVAFAPI, bolsista do Programa Institucional de Bolsa de Iniciação Científica (PIBIC-NOVAFAPI), Teresina, PI - Brasil, e-mail: felipethe@yahoo.com.br

[d] Doutora em Ciências Biológicas pela Universidade Federal de Pernambuco (UFPE), docente do Departamento de Biofísica e Fisiologia da Universidade Federal do Piauí (UFPI), docente da Faculdade NOVAFAPI, Teresina, PI - Brasil, e-mail: carminhamartins@ufpi.edu.br

\section{Resumo}

Introdução: Vários estudos têm sido realizados visando identificar um medicamento que acelere a consolidação de fraturas. Objetivo: Avaliar o efeito do exercício físico e da administração de testosterona no processo de consolidação de fratura de tíbia e fíbula de ratos. Materiais e métodos: Rattus norvegicus (250 a $300 \mathrm{~g}$ ) foram distribuídos aleatoriamente em quatro grupos de oito animais: Controle- fratura e imobilização; G1- fratura, imobilização e propionato de testosterona; G2- fratura, imobilização e treinamento físico de natação; G3- fratura, imobilização, treinamento físico de natação e propionato de testosterona. Os tratamentos foram iniciados imediatamente após a realização de fraturas fechadas no terço médio da tíbia direita. 0 programa de treinamento físico consistiu em 50 minutos de natação durante quatro semanas, cinco vezes por semana. 0 propionato de testosterona $3 \mathrm{mg} / \mathrm{kg}$ foi administrado por via subcutânea cinco vezes na semana durante quatro semanas. As variáveis analisadas incluíram evolução ponderal, tamanho do calo ósseo, níveis séricos de fósforo, cálcio, albumina, proteínas totais e atividade da fosfatase alcalina. 
Resultados: 0 tamanho do calo ósseo foi maior no grupo submetido a tratamento combinando imobilização, exercício físico e testosterona. Os grupos tratados com testosterona combinada ou não a programa de natação apresentaram maiores níveis de fósforo e de fosfatase alcalina, além de menores níveis de proteínas totais e albumina. Conclusão: 0 grupo submetido ao programa de treinamento físico de natação combinado com a administração de testosterona obteve melhor consolidação óssea evidenciada pelo maior calo ósseo e atividade aumentada da fosfatase alcalina, sugerindo maior rapidez no processo de consolidação óssea.

Palavras-chave: Exercício físico. Testosterona. Consolidação da fratura.

\section{Abstract}

Introduction: Several studies have been conducted to identify a drug to accelerate the consolidation of fractures. Objective: To evaluate the effect of physical exercise and the administration of testosterone in the consolidation process of fracture of the tibia and fibula of rats. Materials and methods: Rattus norvegicus (250 to $300 \mathrm{~g}$ ) were randomly assigned to four groups of eight animals: Control-fracture and immobilization; G1-fracture, immobilization and testosterone propionate; G2-fracture, immobilization and physical training of swimming; G3- fracture, immobilization, physical training and swimming testosterone propionate. The treatments started immediately after completion of closed fractures in the middle third of right tibia. The physical training program consisted of 50 minutes of swimming for four weeks, five times a week. The testosterone propionate $3 \mathrm{mg} / \mathrm{kg}$ was administered subcutaneously five times a week for four weeks. The variables analyzed included weight gain, size of bone callus, serum phosphorus, calcium, albumin, total protein and alkaline phosphatase activity. Results: The size of callus was higher in group undergoing treatment combining immobilization, exercise and testosterone. The groups treated with testosterone, combined or not with the swimming program, had higher levels of phosphorus and alkaline phosphatase, and lower levels of total protein and albumin. Conclusion: The group undergoing swimming exercise training combined with the administration of testosterone obtained best evidenced by increased bone callus and alkaline phosphatase activity, suggesting faster bone healing process.

Keywords: Physical exercise. Testosterone. Fracture healing.

\section{Introdução}

O tecido ósseo tem muitas propriedades estruturais interessantes, essencialmente relacionadas à sua composição: hidroxiapatita, colágeno, pequena quantidade de proteoglicanos, proteínas não colágenas e água. 0 osso possui a capacidade de crescer, modificar sua forma, realizar autorreparo quando fraturado e continuamente se renovar, processos governados por padrões mecânicos, hormonais e fisiológicos (1).

A consolidação óssea é um processo complexo que envolve múltiplas fases sobrepostas (2). Embora o desenvolvimento de novos implantes e técnicas cirúrgicas minimamente invasivas tenha contribuído para a melhora na evolução das fraturas e em recuperação funcional precoce, algumas fraturas ainda consolidam irregularmente, outras apresentam atrasos de consolidação e algumas acabam em pseudartroses $(3,4)$. Por essa razão, diversas pesquisas têm sido realizadas buscando identificar medicamentos capazes de acelerar a consolidação de fraturas e melhorar a qualidade do calo ósseo $(3,5,6)$.

No ser humano, a testosterona atua sobre o osso estimulando a retenção de cálcio, o que aumenta a quantidade total de matriz óssea por aumentar a atividade dos osteoblastos, além de estimular o anabolismo proteico, proporcionando aumento da massa muscular $(7,8)$. Estudos indicam que, durante a atividade física de grande intensidade, há aumento nos níveis de testosterona, fato que chama atenção em virtude dos efeitos provocados por esta e pelas implicações e possíveis aplicações clínicas $(2,8,9)$.

A imobilização de um segmento lesado por tempo prolongado é responsável por várias alterações, incluindo modificações nas propriedades mecânicas do sistema musculoesquelético submetido à restrição de movimento (10-12). Alguns estudos demonstram que a realização de atividades físicas regulares durante o 
período de imobilização resulta em vários benefícios, incluindo a manutenção da força, resistência, velocidade e torque muscular, preservação do tecido ósseo, dentre outros $(9,11-13)$. Os marcadores bioquímicos cálcio, fósforo e fosfatase alcalina são indicadores indiretos do processo de neoformação ósseo, uma vez que o cálcio e o fósforo são componentes da matriz óssea e a fosfatase alcalina é um marcador da atividade osteoblástica $(7,8)$. Este estudo avaliou o efeito de exercício físico de natação associado à administração de testosterona no processo de consolidação de fratura de tíbia e fíbula em ratos.

\section{Materiais e métodos}

Foram utilizados 32 ratos albinos da linhagem Wistar, machos, adultos (70-80 dias), com peso corporal inicial variando entre 250 e $300 \mathrm{~g}$, provenientes da colônia do Biotério da Faculdade de Saúde, Ciências Humanas e Tecnológicas do Piauí (NOVAFAPI), os quais foram mantidos em sala climatizada com temperatura ambiente de $25 \pm 2{ }^{\circ} \mathrm{C}$ e fotoperíodo de 12 horas de claro e 12 horas de escuro, em gaiolas coletivas (cinco animais/caixa) com ração padrão para ratos (Labina ${ }^{\circledR}$ - Purina) e livre acesso à água.

Os animais foram distribuídos aleatoriamente em quatro grupos de oito animais: Controle- animais com fratura de tíbia e fíbula direitas, e imobilização da pata posterior direita; G1- fratura de tíbia e fíbula direitas, imobilização e testosterona; G2- fratura de tíbia e fíbula direitas, imobilização e protocolo de treinamento moderado de natação; e G3- fratura de tíbia e fíbula direitas, imobilização, protocolo de treinamento moderado de natação e testosterona.

As fraturas de tíbia e fíbula direitas foram realizadas após anestesia com quetamina (40 mg/kg) e xilazina ( $5 \mathrm{mg} / \mathrm{kg}$ ) i.p. As fraturas foram realizadas na diáfise transversa por flexão forçada seguida de processo de tração-distração para alinhamento dos fragmentos ósseos e imobilização talar. Ainda sob efeito de anestésico foi administrado $0,1 \mathrm{~mL} / 100 \mathrm{~g}$ i.m. de Pencivet ${ }^{\circledR}$ ppu (antibacteriano e anti-inflamatório).

Os animais do grupo G1 e G3 receberam propionato de testosterona em óleo de milho $3 \mathrm{mg} / \mathrm{kg} /$ dia s.c, cinco vezes na semana em dias consecutivos durante quatro semanas. A dose de testosterona baseou-se em padronização de reposição hormonal em modelos experimentais de orquidectomia utilizada neste e em outros laboratórios e compatível com os níveis fisiológicos de testosterona de um animal intacto, utilizada também em trabalhos com administração de testosterona em animais intactos, como no estudo de Chetan et al. (14). Foram feitas aplicações durante todo o protocolo de treinamento, totalizando 20 aplicações subcutâneas, uma vez que a literatura não padroniza a frequência da aplicação do hormônio; encontram-se diferentes esquemas de administração. 0 peso corporal foi determinado semanalmente para ajuste da dose de testosterona e para avaliação da evolução ponderal dos animais dos diferentes grupos estudados.

Os animais dos grupos G2 e G3 foram submetidos a um programa de treinamento físico de natação iniciado um dia após indução das fraturas, o qual consistiu em prática de natação durante 50 minutos por dia, cinco dias por semana durante quatro semanas. Uma semana antes da realização das fraturas, os animais assinalados para compor os grupos treinados foram submetidos a período de adaptação de uma semana no meio aquático com permanência dos animais na água durante 20 minutos por dia, três vezes na semana, com água em temperatura entre 30 e $32^{\circ} \mathrm{C}$ e profundidade da água de $150 \%$ do comprimento do animal, sem a utilização de sobrecarga. Os animais dos grupos sem exercício tiveram suas atividades limitadas à movimentação espontânea dentro da gaiola.

Após quatro semanas de treinamento, os animais foram anestesiados e eutanasiados com doses excessivas de tiopental sódico $(100 \mathrm{mg} / \mathrm{kg}$ ) por via intraperitoneal (15). Foram obtidas amostras de sangue venoso para as dosagens bioquímicas de cálcio, fósforo, fosfatase alcalina, albumina e proteínas totais, por meio de método enzimático colorimétrico com reagentes da Labtest Diagnóstica.

Retirou-se, ainda, a tíbia direita por meio da desarticulação do joelho e da articulação tíbio-társica para avaliação clínica e mensuração do calo ósseo no sentido anteroposterior com paquímetro analógico. A avaliação da mobilidade da fratura foi realizada utilizando escala de 0 a 2 (grau 0: fratura consolida$\mathrm{da}$, sem mobilidade ao teste manual; grau 2: quando ocorrer mobilidade franca, e grau 1 ao padrão intermediário de movimentação).

Para a análise estatística, utilizou-se o teste $t$ pareado para comparar as diferenças dentro dos grupos em termos de variação ponderal, e Anova seguida de pós-teste de Tukey para comparação entre grupos. 0 nível de significância estabelecido foi de $\mathrm{p}<0,05$. Os dados estão apresentados como média \pm EPM (erro padrão da média). 
O estudo foi aprovado pelo Comitê de Ética em Pesquisa da NOVAFAPI (Parecer n. 013-08), e todos os procedimentos foram realizados em concordância com os princípios éticos para experimentação animal segundo as diretrizes internacionais estabelecidas pela Pain em 1983.

\section{Resultados}

Neste estudo, não foram encontradas diferenças estatisticamente significativas $(\mathrm{p}>0,05)$ na variação ponderal ao longo do período experimental nos grupos avaliados, e entre grupos ao final do período de tratamento. No Quadro 1, são apresentados os resultados relativos ao tamanho do calo ósseo nos diferentes grupos experimentais. Observou-se que, ao final do período de acompanhamento, o calo ósseo foi significativamente menor no grupo controle $(0,47 \pm 0,02)$ e no grupo tratado com propionato de testosterona - G1 $(0,48 \pm 0,02)$, se comparados ao grupo tratado com testosterona e submetido ao programa de natação - G3 $(0,58 \pm$ $0,03)$. Ao teste de mobilidade manual da fratura, $37,5 \%$ dos animais do grupo controle apresentaram mobilidade grau 2, no G1 85,72\% dos animais foram classificados em grau 0 e $14,28 \%$ no grau 1 , enquanto nos grupos G2 e G3, 100\% dos animais apresentaram mobilidade nula.

Em relação aos marcadores bioquímicos, os níveis séricos de fósforo (Quadro 2) foram significativamente maiores $(p<0,05)$ em G1 $(8,8 \pm 0,82)$ e G3 $(6,9 \pm$ $0,61)$, quando comparados ao grupo controle $(5,7 \pm$

Quadro 1 - Tamanho do calo ósseo medido em animais submetidos à fratura de tíbia após quatro semanas de tratamento

\begin{tabular}{lc}
\hline Grupo & $\begin{array}{c}\text { Tamanho do calo ósseo } \\
(\mathrm{mm})(\text { média } \pm \text { EPM) }\end{array}$ \\
\hline Grupo Controle & $0,47 \pm 0,02$ \\
G1 & $0,48 \pm 0,02$ \\
G2 & $0,51 \pm 0,01$ \\
G3 & $0,58 \pm 0,03^{\mathrm{a}}$ \\
\hline
\end{tabular}

Fonte: Dados da pesquisa.

Legendas: $a=p<0,05$ (Anova e pós-teste de Tukey) em relação ao grupo controle e G1; EPM = Erro padrão da média.
$0,22)$ e a G2 $(4,3 \pm 0,57)$. Não foram encontradas diferenças nos níveis séricos de cálcio entre os grupos.

Os níveis séricos de albumina foram mais elevados $(\mathrm{p}<0,005)$ no grupo controle e no grupo submetido a protocolo de natação (G2) em relação ao grupo tratado com propionato de testosterona isoladamente (G1) ou associado a programa de natação (G3). Os níveis de proteínas totais mostraram-se significativamente superiores $(p<0,0001)$ no grupo controle. A atividade da fosfatase alcalina (Quadro 2) foi significativamente maior no grupo tratado com propionato de testosterona isoladamente $(\mathrm{p}<0,0001)$ e no grupo tratado com propionato de testosterona associado à programa de natação $(\mathrm{p}<0,0005)$ quando comparados ao grupo submetido à imobilização isolada (grupo controle) ou combinada com treinamento físico de natação (G2).

\section{Discussão}

A ocorrência de mobilidade nula, verificada por meio do teste manual de mobilidade da fratura nos animais submetidos ao protocolo de natação (grupos G2 e G3) em comparação com o maior grau de mobilidade evidenciada nos grupos controle e G1, corrobora a hipótese de que a atividade física acelera o processo de reparo da fratura $(16,17)$. Destacase, ainda, que o tamanho do calo ósseo parece ser um fator determinante na ausência de mobilidade ao teste manual de mobilidade da fratura, visto que se observou calo ósseo significativamente maior no grupo G3 em comparação com o grupo controle $(\mathrm{p}<0,05)$, além de haver tendência ao aumento de formação do calo ósseo em G2 (Quadro 2).

Vários fatores contribuem para o processo de reparo ósseo, e dentre eles destacam-se a presença de mobilidade no sítio fraturário, o suprimento sanguíneo e os ambientes biomecânico, eletromagnético e bioquímico (18). Para Jagodzinski (4), o estímulo predominante para a proliferação celular no reparo das fraturas é a perfusão. A atividade física pode modificar vários fatores importantes para a reparação óssea. Uma hipótese proposta por alguns pesquisadores $(19,20)$ para o efeito da atividade física é a de que a contração muscular levaria a uma melhora do processo de consolidação óssea por aumentar o fluxo sanguíneo. Contudo, Grundnes e Reikeras (21) demonstraram não haver alteração do fluxo sanguíneo no sítio da fratura em decorrência da atividade física 
Quadro 2 - Níveis séricos de fósforo, cálcio, albumina, proteínas totais e atividade da fosfatase alcalina após quatro semanas de tratamento em animais submetidos à fratura de tíbia

\begin{tabular}{lcccc}
\hline Parâmetro & $\begin{array}{c}\text { Controle } \\
\text { (média } \pm \text { EPM) }\end{array}$ & $\begin{array}{c}\text { G1 } \\
\text { (média } \pm \text { EPM) }\end{array}$ & $\begin{array}{c}\text { G2 } \\
\text { (média } \pm \text { EPM) }\end{array}$ & $\begin{array}{c}\text { G3 } \\
\text { (média } \pm \text { EPM) }\end{array}$ \\
\hline Fósforo (mg/dL) & $5,7 \pm 0,22$ & $8,8 \pm 0,82^{\mathrm{a}, \mathrm{b}}$ & $4,3 \pm 0,57$ & $6,9 \pm 0,61^{\mathrm{c}}$ \\
Cálcio $(\mathrm{mg} / \mathrm{dL})$ & $7,9 \pm 1,30$ & $11,2 \pm 0,43$ & $8,7 \pm 0,76$ & $11,3 \pm 0,63$ \\
Albumina (g/dL) & $3,5 \pm 0,11^{\mathrm{d}}$ & $2,8 \pm 0,15$ & $5,7 \pm 2,69^{\mathrm{d}}$ & $2,3 \pm 0,11$ \\
Proteínas totais (g/dL) & $8,1 \pm 0,14^{\mathrm{e}}$ & $4,0 \pm 0,08$ & $3,6 \pm 0,20$ & $3,3 \pm 0,14$ \\
Fosfatase alcalina (U/L) & $10,9 \pm 3,69$ & $54,9 \pm 3,98^{\mathrm{f}}$ & $4,6 \pm 0,19$ & $40,0 \pm 3,15 \mathrm{~g}$ \\
\hline
\end{tabular}

Legenda: $\mathrm{EPM}=$ Erro padrão da média. ANOVA e pós-teste de Tukey - Fósforo: ap < 0,0005 em relação a grupo controle, bp < 0,001 em relação a G2, cp < 0,05 em relação a G2. Albumina: dp < 0,005 em relação a G1 e G3. Proteínas Totais: ep < 0,0001 em relação a G1, G2 e G3. Fosfatase alcalina: $f p<0,0001$ em relação ao grupo controle e G1, gp < 0,0005 em relação ao grupo controle e G1.

Fonte: Dados da pesquisa.

nem correlação entre massa do calo ósseo e o fluxo sanguíneo no mesmo. Outro possível mecanismo envolvido no efeito da atividade física é que a contração muscular gere movimento interfragmentário no local da fratura, um conhecido estimulador do processo de reparo ósseo (22-26), enquanto a eliminação de tais movimentos suprime a formação do calo externo, fazendo com que o reparo seja feito por um processo primário de contato (27).

Além disso, os estímulos mecânicos iniciam uma cadeia de eventos envolvendo mensageiros intracelulares que resultam em formação óssea e aumento na massa óssea por efeitos na codificação celular apropriada $(4,28,29)$. Tais estímulos atuando sobre os cristais de hidroxiapatita e sobre o colágeno também criam um campo de força eletromagnética que estimula os osteoblastos a produzirem matriz óssea no sentido da força imposta, o que é conhecido como efeito piezoelétrico (30-32).

Além disso, o exercício físico induz várias alterações hormonais, dentre elas o aumento dos níveis séricos de testosterona e de calcitonina, grandes estimuladores da retenção de cálcio nos ossos, além de aumento da atividade dos osteoblastos, da síntese de proteínas na matriz extracelular, da diferenciação e mineralização óssea, e de inibir a ação dos osteoclastos (33).

Em contrapartida, principalmente quando administrada em doses para níveis suprafisiológicos, a testosterona pode produzir efeitos deletérios, tais como: policitemia, disfunção hepática e alterações no perfil lipídico (34). 0 desenvolvimento de policitemia parece ser proporcional à dose suprafisiológica de testosterona administrada e é explicado tanto por estimular a produção renal de eritropoetina quanto pelo efeito direto sobre as células progenitoras formadoras de colônias eritrocitárias (35). As alterações no perfil lipídico são caracterizadas por concentrações diminuídas de Lipoproteína de Alta Densidade (HDL) e aumentadas de Lipoproteína de Baixa Densidade (LDL) (36). Com relação às alterações da função hepática, alguns estudos apontam que o uso de esteroides anabolizantes androgênicos pode causar icterícia colestática, peliose hepática, lesões e tumores hepáticos e adenomas hepatocelulares (37), além de existirem relatos de elevações de enzimas hepáticas (aspartato aminotransferase-AST, alanina aminotransferase -ALT e creatina kinase -CK) secundárias ao uso de esteroides anabolizantes (38).

A análise dos níveis séricos de cálcio e fósforo em associação com a atividade da fosfatase alcalina sugere sinais de consolidação óssea ativa no grupo tratado com propionato de testosterona, provavelmente por aumento na atividade osteoblástica $(39,40)$. Isso poderia ser explicado pela suprarregulação de receptores androgênicos no osso, e pelo efeito direto da ativação de tais receptores na atividade de condrócitos, osteoclastos, osteoblastos e de seus progenitores (33).

Kasper (41) demonstrou que os andrógenos estimulam diretamente a proliferação de osteoblastos in vitro e a análise da ação isolada dos andrógenos sobre as células osteoblásticas isoladas induz a expressão da fosfatase alcalina, um fator de proliferação osteoblástica. Também revelou que esse mecanismo é ativado diretamente, por meio de receptores de andrógenos localizados nos osteoblastos que aumentam 
a síntese de DNA e a diferenciação, ou através da aromatização do andrógeno.

Pesquisadores têm demonstrado que a ativação do receptor androgênico (RA) em osteoblastos é responsável pelo desenvolvimento e manutenção da massa óssea trabecular $(42,43)$ e que a inativação das vias de sinalização relacionadas ao RA, especificamente em osteblastos maduros, resulta em reabsorção óssea aumentada e diminuição da integridade estrutural óssea (44). Adicionalmente, Sinnesael et al. (45) verificaram que a inativação seletiva dos receptores androgênicos em osteócitos acelera a deterioração da integridade esquelética, e sugerem que os andrógenos desempenhem papel direto na manutenção de osso trabecular através da ação no RA de osteócitos, e não apenas de osteoblastos.

Em oposição aos valores aumentados de fosfatase alcalina e cálcio sérico, os valores de albumina e proteínas totais mostraram-se menores nos grupos tratados com propionato de testosterona. Tal fato poderia sugerir menor deposição cálcica no calo ósseo, visto que a albumina é o principal meio de transporte sérico do cálcio. No entanto, os resultados relativos a níveis de cálcio sérico, tamanho do calo ósseo e taxa de imobilidade das fraturas ao teste manual evidenciam que mesmo frente aos baixos valores de albumina e proteínas totais, o propionato de testosterona sozinho ou associado ao exercício (G1 e G3) foi suficiente para prover o cálcio necessário. Assim, a ação anabólica da testosterona resultando em diminuição da taxa de proteínas totais e albumina $(46,47)$ foi superada pela estimulação celular direta exercida pelo andrógeno no osso (33).

$A$ atividade da fosfatase alcalina elevada, menor concentração de fósforo sérico, maior calo ósseo e fratura consolidada, evidenciada pela ausência de mobilidade ao teste manual, encontrados no grupo submetido ao protocolo de natação combinado com tratamento com propionato de testosterona indicam que a reparação óssea iniciou-se precocemente e que o processo de deposição de minerais na neoformação da matriz óssea foi mais eficiente. De forma semelhante ao grupo submetido ao programa de exercício físico de natação associado à administração de testosterona, 0 grupo submetido apenas ao programa de natação também obteve bom perfil osteometabólico, e foi possível constatar ação positiva da administração de testosterona nesses animais, especialmente no aumento da atividade da fosfatase alcalina e no tamanho do calo ósseo, favorecendo o processo de neoformação óssea.

\section{Conclusão}

A associação dos altos níveis de fosfatase alcalina, maior calo ósseo e a imobilidade da fratura ao teste manual no grupo submetido a protocolo de treinamento aeróbio de natação combinado com a administração de propionato de testosterona indicam consolidação óssea em fase avançada. Embora o grupo tratado com propionato de testosterona tenha apresentado níveis mais elevados de marcador do metabolismo ósseo, tais achados podem sugerir metabolismo de reparo ósseo em fase inicial. Além disso, neste estudo a testosterona mostrou-se poderoso indutor do reparo ósseo, haja vista seu efeito sobre o tamanho do calo ósseo e a atividade da fosfatase alcalina.

Ressalta-se a necessidade de novos estudos, incluindo a avaliação de outros marcadores bioquímicos mais específicos do metabolismo ósseo, bem como avaliação histológica do processo de reparo ósseo, divididos em etapas, a fim de que se elucidem os reais potenciais da atividade física e do propionato de testosterona no processo de reparo ósseo para uso clínico.

\section{Referências}

1. Doblaré M, Garcia JM, Gómez MJ. Modelling bone tissue fracture and healing: a review. Eng Fract Mech. 2004;71(13-14):1809-40. doi:10.1016/j. engfracmech.2003.08.003.

2. Vialle E. Produção de fratura padronizada de fêmur em ratos. Rev Bras Ortop. 2004; 39(6):323-9.

3. Cadore EL, Michel AB, Kruel LFM. Efeitos da atividade física na densidade mineral óssea e na remodelação do tecido ósseo. Rev Bras Med Esporte. 2005;11(6):373-9. doi:10.1590/S1517-86922005000600013.

4. Jagodzinski M, Krettek C. Effect of mechanical stability on fracture healing - an update. Injury. 2007;38 Suppl 1:S3-10. doi:10.1016/j.injury.2007.02.005.

5. Ferreira DB Júnior. Alendronato de sódio, risedronato sódico, atorvastatina cálcica e lovastatina na reparação de fraturas tibiais em ratas com osteoporose induzida pela dexametasona [dissertação]. Viçosa: Universidade Federal de Viçosa; 2007. 
6. Piai CR, Carvalho VAP, Werkman C, Anbinder AL, Rocha, RF. Efeitos do risedronato na reparação óssea de ratos machos e fêmeas com osteopenia. Cienc Odontol Bras. 2005;8(3):77-82.

7. Canali ES, Kruel LFM. Respostas hormonais ao exercício. Rev Paul Educ Fís. 2001;15(2):141-53.

8. Lapin LP. Respostas metabólicas e hormonais ao exercício físico. Rev Bras Educ Física Esporte Lazer Dança. 2007;2(4):115-24.

9. Daniela CL. Tratamentos não farmacológicos na estimulação da osteogênese. Rev Saúde Pública. 2002;36(5): 647-54. doi:10.1590/S0034-89102002000600017.

10. Lima SC. Curto período de imobilização provoca alterações morfométricas e mecânicas no músculo de rato. Rev Bras Fisioter. 2007;11(4):297-302. doi:10.1590/ S1413-35552007000400009.

11. Greenleaf JE, Kozlowski S. Physiological consequences of reduced physical activity during bed rest. Exerc Sport Sci Rev. 1982;10:84-119. doi:10.1249/ 00003677-198201000-00004.

12. Krasnoff J, Painter P. The physiological consequences of bed rest and inactivity. Adv Ren Replace Ther. 1999;2(6):124-32.

13. Shinohara M, Yoshitake Y, Kouzaki M, Fukuoka H, Fukunaga T. Strenght training counteracts motor performance losses during bed rest. J Appl Physiol. 2003;95:1485-92. PMid:12832434

14. Chetan N, Alok N, Dixit VK. Effect of benincasa hispida fruits on testosterone-induced prostatic hypertrophy in albino rats. Cur Ther Res. 2010;71(5):331-43. doi:10.1016/j.curtheres.2010.10.006.

15. Massone F. Anestesiologia veterinária. Farmacologia e técnicas. 4. ed. Rio de Janeiro: Guanabara Koogan; 2003.

16. Bailón-Plaza A, van der Meulen MCH. Beneficial effects of moderate, early loading and adverse effects of delayed or excessive loading on bone healing. J Biomech. 2003;36:1069-77. doi:10.1016/ S0021-9290(03)00117-9.

17. Guerino MR, Santi FP, Silveira RF, Luciano E. Influence of ultrasound and physical activity on bone healing. Ultrasound Med Biol. 2008;34(9):1408-13. doi:10.1016/j.ultrasmedbio.2008.02.006.
18. Wraighte PJ, Scammell BES. Principles of fracture healing. Surgery. 2006;24(6):198-207. doi:10.1383/ surg.2006.24.6.198.

19. Park S, Silva M. Neuromuscular electrical stimulation enhances fractures healing: results of an animal model. J Orthopaed Res. 2004;22:382-87. doi:10.1016/j. orthres.2003.08.007.

20. Nordsletten L, Skjeldal S, Kirkeby OJ, Ekeland A. Muscle contraction increases the strength of healing tibial fracture in the rat. Acta Orthop Scand. 1994;65(2):1914. doi:10.3109/17453679408995432.

21. Grundnes 0, Reikeras O. Effect of physical activity on muscle and blood flow after fracture. Exercise and tenotomy studied in rats. Acta Orthop Scand.1991;62(1):67-9. doi:10.3109/ 17453679108993096.

22. Park S, O`Connor K, Mckellop H, Sarmiento A. The influence of active shear or compressive motion on fracture-healing. J Bone Joint Surg. 1998;80:868-78. PMid:9655105.

23. Park S, O`Connor K, Mckellop H. Interaction between active motion and exogenous transforming growth factor beta during tibial fracture rapair. J Orthop Trauma. 2003;17:2-10. doi:10.1097/ 00005131-200301000-00002.

24. Klein P, Schell H, Streitparth F, Heller M, Kassi J, Kandziora F, et al. The initial phase of fracture healing is specifically sensitive to mechanical conditions. J Orthop Res. 2003;21:662-9. doi:10.1016/ S0736-0266(02)00259-0.

25. Smith-Adaline EA, Volkman SK, Ignelzi MA Junior, Slade J, Platte S, Goldstein SA. Mechanical environment alters tissue formation patterns during fracture repair. J Orthop Res. 2004;22:1079-85. doi:10.1016/j. orthres.2004.02.007.

26. Yamaji T, Ando K, Wolf S, Augat P, Claes L. The effect of micromovement on callus formation. J Orthop Sci. 2001;6(6):571-5. doi:10.1007/s007760100014.

27. Henderson CE, Bottlang M, Marsh JL, Fitzpatrick DC, Madey SM. Does locked plating of periprosthetic supracondylar femur fractures promote bone healing by callus formation? Two cases with opposite outcomes. Iowa Orthop J. 2008;28:73-6. PMid:19223952. 
28. Isaksson HE. Mechanical and mechanobiological influences on bone fracture repair. [tese]. PHD - Engenharia Biomédica. Eindhoven: Eindhoven University of Technology; 2007.

29. Sinaki M. The role of physical activity in bone health: a news hypothesis to reduce risk of vertebral fracture. Phys Med Rehabil Clin N Am. 2007;18:593-608. doi:10.1016/j.pmr.2007.04.002.

30. Lirani APR, Lazaretti-castro M. Evidências da ação de agentes físicos sobre o metabolismo do tecido ósseo e seus potenciais usos clínicos. Arq Bras Endocrinol Metab. 2005;49(6):891-6. doi:10.1590/ S0004-27302005000600006.

31. Fukada E, Yasuda I. On the piezoelectric effect of bone. J Physic Soc Jpn. 1957;12:1158-62. doi:10.1143/ JPSJ.12.1158.

32. Lind M, Bunger C. Factor stimulating bone formation. Eur Spine J. 2001;10:102-9. doi:10.1007/ s005860100269.

33. Notelovitz M. Androgen effects on bone and muscle. Fertil Steril. 2001;77(4):34-41.

34. Seal LJ. Testosterone replacement therapy. Medicine. 2009;37(9):445-9. doi:10.1016/j.mpmed. 2009.06.002.

35. Zitzmann $M$. Issues in testosterone management: terminology, safety, genetics. J Mens Health. 2008;5(Suppl):S35-39. doi:10.1016/j.jomh.2008.03.015.

36. Bhasin S. Effects of testosterone administration on fat distribution, insulin sensitivity, and atherosclerosis progression. 2003;37(Suppl2):S142-9.

37. Hoffman JR, Ratamess NA. Medical issues associated with anabolic steroid use: are they exaggerated? J Sports Sci Med. 2006;5:182-193.

38. Dickerman RD, Pertusi RM, Zachariah NY, Dufour DR, McConathy WJ. Anabolic steroid-induced hepatotoxicity: Is it overstated? Clin. J. Sport Med. 1999;9:34-39. doi:10.1097/00042752-199901000-00007.

39. Mayr-Wohlfart U, Fiedler J, Gunther KP, Puhl W, Kessler S. Proliferation and differentiation rates of a human osteoblast-like cell line (SaOS-2) in contact with different bone substitute materials. J Biomed Mater Res. 2001;57:132-9. doi:10.1002/1097-4636(200110)57:1<132::AID-JBM1152>3.0.CO;2-K.
40. Taniguchi T, Matsumoto T, Shindo H. Changes of serum levels of osteocalcin, alkaline phosphatase, IGF-I and IGF-binding protein-3 during fracture healing. Injury. 2003;34(7):477-9. doi:10.1016/ S0020-1383(02)00380-7.

41. Kasper $\mathrm{CH}$, Wergedal JE, Farley JR, Linkhart TA, Turner RT, Baylink DJ. Androgens direct stimulate proliferation of bone cells in vitro. Endocrinol. 1989;124(3):1576-8. doi:10.1210/endo-124-3-1576.

42. Callewaert F, Venken K, Ophoff J, de Gendt K, Torcasio A, van Lenthe GH, et al. Differential regulation of bone and body composition in male mice with combined inactivation of androgen and estrogen receptor-alpha. FASEB J. 2009;23(1):232-40. doi:10.1096/ fj.08-113456.

43. Chiang C, Chiu M, Moore AJ, Anderson PH, GhasemZadeh A, McManus JF, et al. Mineralization and bone resorption are regulated by the androgen receptor in male mice. J Bone Miner Res. 2009;24(4):621-31. doi:10.1359/jbmr.081217.

44. Notini AJ, McManus JF, Moore A, Bouxsein M, Jimenez M, Chiu WS, et al. Osteoblast deletion of exon3 of the androgen receptor gene results in trabecular bone loss in adult male mice. J Bone Miner Res. 2007;22(3):34756. doi:10.1359/jbmr.061117.

45. Sinnesael M, Claessens F, Laurent M, Dubois V, Boonen $\mathrm{S}$, Deboel L, et al. Androgen receptor (AR) in osteocytes is important for the maintenance of male skeletal integrity: evidence from targeted AR disruption in mouse osteocytes. J Bone Miner Res. 2012;27(12):2535-43. doi: 10.1002/jbmr.1713.2012.

46. Manolagas SC, Kousteni S, Jilka RL. Sex steroids and bone. Recent Prog Horm Res. 2002;57:385-409. doi:10.1210/rp.57.1.385.

47. Oliveira LAO. Avaliação do efeito do risedronato sódico na consolidação de fraturas: estudo experimental em ratos. Acta Ortop Bras. 2004;12(2):77-83. doi:10.1590/S1413-78522004000200002.

Recebido: 11/07/2011 Received: 07/11/2011

Aprovado: 18/12/2011 Approved: 12/18/2011 